OPEN ACCESS

Edited by:

Andrea Mozzarelli,

Università degli Studi di Parma, Italy

Reviewed by:

Ashok Kumar,

University of Florida, United States

Silvia Sacchi,

Università degli Studi dell'Insubria, Italy

*Correspondence:

Jean-Marie Billard

jean-marie.billard@inserm.fr

Specialty section:

This article was submitted to

Structural Biology

a section of the journal

Frontiers in Molecular Biosciences

Received: 21 September 2018 Accepted: 09 November 2018

Published: 28 November 2018

Citation:

Billard J-M (2018) Changes in Serine Racemase-Dependent Modulation of

NMDA Receptor: Impact on

Physiological and Pathological Brain

Aging. Front. Mol. Biosci. 5:106.

doi: 10.3389/fmolb.2018.00106

\section{Changes in Serine} Racemase-Dependent Modulation of NMDA Receptor: Impact on Physiological and Pathological Brain Aging

\author{
Jean-Marie Billard * \\ UNICAEN, INSERM, COMETE, Normandie University, Caen, France
}

The N-methyl-D-Aspartate glutamate receptors (NMDARs) are pivotal for the functional and morphological plasticity that are required in neuronal networks for efficient brain activities and notably for cognitive-related abilities. Because NMDARs are heterogeneous in subunit composition and associated with multiple functional regulatory sites, their efficacy is under the tonic influence of numerous allosteric modulations, whose dysfunction generally represents the first step generating pathological states. Among the enzymatic candidates, serine racemase (SR) has recently gathered an increasing interest considering that it tightly regulates the production of D-serine, an amino acid now viewed as the main endogenous co-agonist necessary for NMDAR activation. Nowadays, SR deregulation is associated with a wide range of neurological and psychiatric diseases including schizophrenia, amyotrophic lateral sclerosis, and depression. This review aims at compelling the most recent experimental evidences indicating that changes in SR-related modulation of NMDARs also govern opposite functional dysfunctions in physiological and pathological (Alzheimer's disease) aging that finally results in memory disabilities in both cases. It also highlights SR as a relevant alternative target for new pharmacological strategies aimed at preventing functional alterations and cognitive impairments linked to the aging process.

Keywords: NMDA receptors, serine racemase, aging, Alzheimer's disease, D-serine, long term potentiation, glutamate

\section{INTRODUCTION}

Through the fine regulation of neurotransmitters/neuromodulators availability at their respective binding sites, enzymatic activities are critical for normal brain functions and are generally targeted by pathophysiological processes. In this context, the modulation of the N-methyl-D-Aspartate subtype of glutamate receptors (NMDARs) certainly represents a school case, which actually focuses the attention of a large proportion of the scientific community as illustrated by the almost 5,000 review articles referenced in pubmed. In fact, based on their large distribution throughout the nervous system and their diversity in subunit composition associated with regional specificity 
in the brain and even with segregated localization at synapse level (see Paoletti et al., 2013; Zhu and Paoletti, 2015), NMDARs thus appear as a perfect example to evaluate the impact of specific allosteric regulation of selective brain activities and notably of cognitive capacities, in normal and pathological conditions. These receptors are complex entities under the modulation of a wide range of regulatory processes driven by magnesium, polyamines and histamine environments as well as levels of redox state (Johnson and Ascher, 1990; Kleckner and Dingledine, 1991; Lipton et al., 1998; Choi and Lipton, 2000; Brown et al., 2001; Haas et al., 2008; Zhu and Paoletti, 2015). Beside these salient regulation features, NMDAR activation is also characterized by the obligatory fixation in addition to the main agonist glutamate of a co-agonist at a specific binding site (Traynelis et al., 2010; Paoletti, 2011; Paoletti et al., 2013). Attributed initially to glycine (Johnson and Ascher, 1987, 1992; Kleckner and Dingledine, 1988), this role of co-agonist in much brain area and particularly in those involved in cognitive functions, is now devoted to D-serine (Schell et al., 1997; Mothet et al., 2000; Snyder and Kim, 2000; Shleper et al., 2005; Billard, 2008, 2012; Henneberger et al., 2012; Bardaweel et al., 2014; Wolosker, 2018), a D-amino acid produced by the racemisation of L-serine by the enzyme serine racemase (SR) (Wolosker et al., 1999). Like the degradation of D-serine (Mothet et al., 2000; Shleper et al., 2005; Strick et al., 2011; Papouin et al., 2012; Rosenberg et al., 2013; Le Bail et al., 2015), the genetic deletion of SR impairs the connectivity and the functional plasticity of neuronal networks and has been associated with cognitive impairments (Inoue et al., 2008, 2018; Basu et al., 2009; Labrie et al., 2009; Balu and Coyle, 2012; Bai et al., 2014; Puhl et al., 2017; Balu et al., 2018). Consequently, changes in SR-dependent modulation of NMDAR activation through alterations of synaptic availability of D-serine, have been postulated to contribute to pathophysiological mechanisms governing several neurological diseases [reviewed in Billard (2013) and Coyle and Balu (2018)]. Thus, weaker NMDAR activation linked to down regulation of SR activity is now viewed as a critical synaptic dysfunction in schizophrenia, addictions, anxiety disorders, and depression (Coyle, 2006; Benneyworth and Coyle, 2012; Gómez-Galán et al., 2012; Coyle and Balu, 2018). On the opposite, up regulation of NMDAR activity due to increased production of D-serine by SR is viewed as a central mechanism for neurodegenerative processes underlying the amyotrophic lateral sclerosis (Sasabe et al., 2007; Lee et al., 2017; Kondori et al., 2018).

In the last decades, the role of SR-dependent regulation of NMDAR activity in cognitive aging has also been investigated, that is the focus of the present review. After recapitulating our knowledge that now considers NMDAR modulation by SR as an essential mechanism involved in learning and memory, currently available information related to its deregulation in physiological aging and Alzheimer's disease (AD) will be presented, with the main conclusion that a strict regulation of SR activity is required for a successful cognitive aging. This review could also offer new opportunities for considering new relevant pharmacological strategies specifically targeting the SR-associated pathway to treat memory deficits linked to age-related brain disorders.

\section{NMDA RECEPTORS: STRUCTURE AND FUNCTIONAL REGULATION}

NMDARs are part of a large multiprotein complex at glutamatergic synapses, that have received much attention over the last decades, due to their role in many types of neural plasticity on the one hand, and their involvement in neurotoxicity on the other hand. They are hetero-tetramers generally formed by two GluN1 subunits associated with the combination of two other partners including either four distinct GluN2 (GluN2A-D) or a mixture of GluN2 with two different GluN3 (GluN3A and 3B) subunits (Ulbrich and Isacoff, 2008; Traynelis et al., 2010; Paoletti, 2011; Paoletti et al., 2013) (Figure 1). The GluN1 subunit is expressed throughout the brain since it is mandatory for NMDAR activation through the necessary binding of a co-agonist at the amino-terminal domain of the extracellular region (Ballard et al., 2002; Paoletti et al., 2013). Besides, GluN2 subunits specifically bind the main agonist glutamate and differ from each other by their pharmacological profiles and also by providing distinct functional properties to NMDARs (Nakanishi and Masu, 1994; Dingledine et al., 1999; Hofmann et al., 2000; Paoletti et al., 2013). Although the wide range of subunit associations predicts a large diversity within the NMDARs family, preferential combinations have been regionally detected in the brain that is also observed at synaptic levels where GluN2A and GluN2B subunits are enriched at postsynaptic densities and extrasynaptic zones respectively (Traynelis et al., 2010; Paoletti, 2011; Paoletti et al., 2013). Important in the context of aging, GluN1 expression remains elevated throughout lifespan (Laurie and Seeburg, 1994; Monyer et al., 1994) whereas a progressive decrease in the GluN2B/GluN2A ratio generally occurs with age at cortical synapses (Monyer et al., 1994; Stocca and Vicini, 1998; Liu et al., 2004; Swanger and Traynelis, 2018), that have suggested the interest of pharmacologically targeting the GluN2B subunit to treat or prevent age-related memory decline (Wang et al., 2014).

In contrast to their diversity in subunit composition, all NMDARs are structurally homogenous (Figure 1) and characterized by three helices (M1, M3, M4) and a hairpin (M2) that form a transmembrane domain allowing the ion selectivity of the receptors. While this domain is subjected to tonic modulation, notably by magnesium $\left(\mathrm{Mg}^{2+}\right)$, this is not the case for the cytoplasmic carboxy-terminal intracellular domain that controls the coupling to different intracellular signaling cascades and the receptor trafficking (Traynelis et al., 2010; Paoletti, 2011; Paoletti et al., 2013).

Compared to the other subtypes of ionotropic glutamate receptors, NMDARs display distinct functional properties identified by slow gating and deactivating kinetics associated with high calcium permeability, which depend on the subunit composition (Dunah et al., 1999; Paoletti, 2011; Wyllie et al., 2013; Zhang and Luo, 2013; Sun et al., 2017). In addition to their specific voltage-dependent blockade by $\mathrm{Mg}^{2+}$ (Johnson and Ascher, 1990; Kleckner and Dingledine, 1991), another impressive functional feature of NMDARs consists in their activation processes which require not only the binding of 


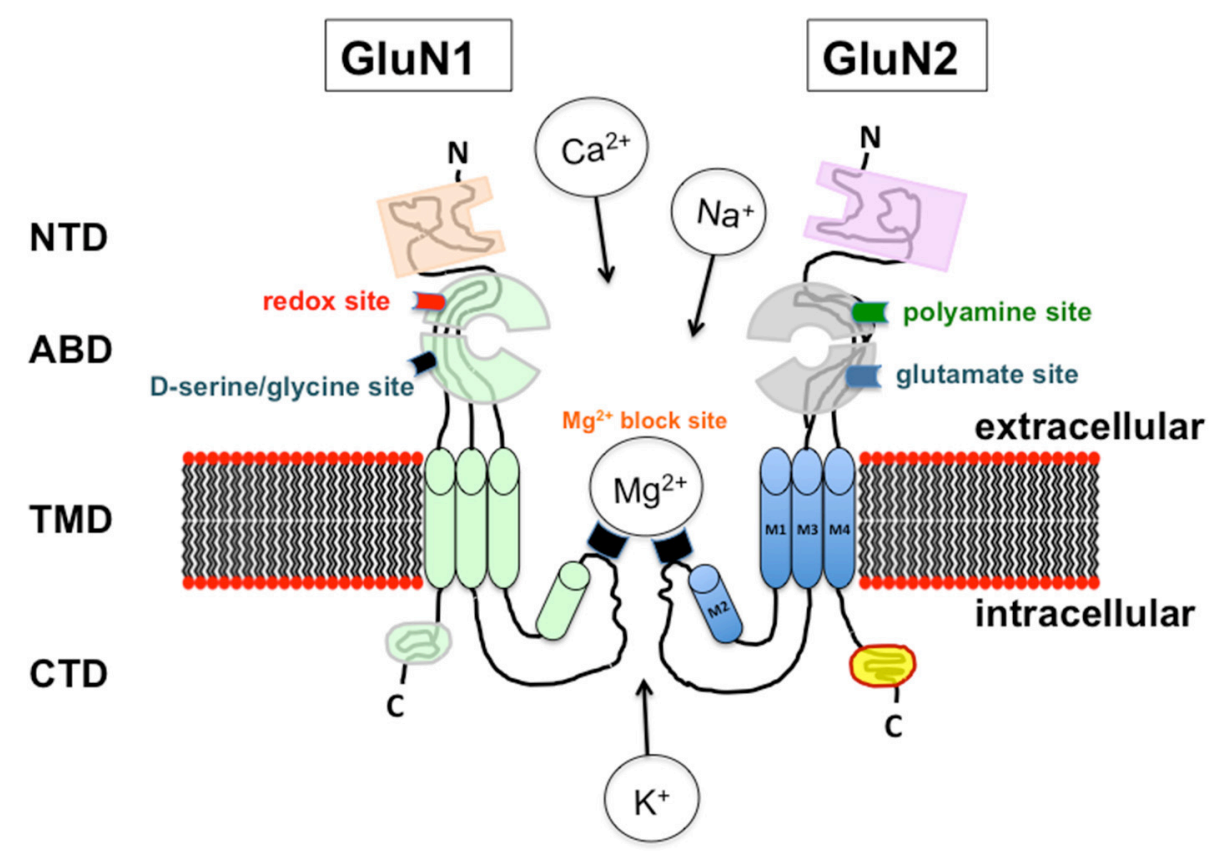

FIGURE 1 | Schematic representation of the assembly and modular organization of a N-Methyl-D-Aspartic acid receptor (NMDAR). The extracellular segment includes the N-terminal domain (NTD) and the agonist binding domain (ABD) where D-serine /glycine and glutamate bind to the GluN1 and GluN2 subunit respectively. $\mathrm{ABD}$ also contains the redox and polyamine regulatory sites. The ion channel is localized in the transmembrane domain (TMD) that contains the site for the magnesium blockade while the C-terminal domain (CTD) is included in the intracellular segment.

glutamate on GluN2 subunits but in synergy, the fixation of a co-agonist on a specific site present on the GluN1 components (Traynelis et al., 2010; Paoletti, 2011). This necessity of a dual binding was initially characterized in the late $80 \mathrm{~s}$ when the induction magnitude of inward currents through native or NMDARs expressed in oocytes (Kleckner and Dingledine, 1988) or in cultured mouse neurons (Johnson and Ascher, 1987) was found to closely rely on glycine levels present in the external medium, thus revealing the existence of the so-called glycine-binding site. After more than 20 years of biochemical, immunohistochemical and electrophysiological investigations [reviewed in Billard (2012)], the initial view of glycine as the endogenous NMDAR co-agonist has then been progressively substituted by the concept assigning this role to the amino acid Dserine, though the most recent emerging view now considers that $\mathrm{D}$-serine rather cooperates with glycine in a complex interplay to control NMDAR activation following time and space constraints (Mothet et al., 2015). D-serine is directly converted from its precursor enantiomer L-serine by the activity of the pyridoxal 5-phosphate (PLP)-dependent enzyme serine racemase (SR) (Wolosker et al., 1999). Interestingly, this enzyme is also able to metabolize D-serine into pyruvate and ammonia by catalyzing an $\alpha, \beta$ elimination of water (De Miranda et al., 2002; Foltyn et al., 2005). This reaction may represent an alternative route to degrade $\mathrm{D}$-serine in forebrain regions where the endogenous degrading enzyme D-amino acid oxidase DAAO (Pollegioni et al., 2007), is poorly expressed (Bendikov et al., 2007; Verrall et al., 2007; Jagannath et al., 2017). However, since the efficacy of the racemisation process of $\mathrm{L}$-serine is five times higher than the reaction of $\alpha, \beta$ elimination (Strísovský et al., 2005), one generally considers that SR preferentially governs D-serine synthesis.

\section{SERINE RACEMASE: LOCALIZATION, REGULATION AND CONTRIBUTION TO FUNCTIONAL PLASTICITY AT SYNAPSES}

Nowadays, the question to know if SR is expressed in a specific cellular population at synapses is heavily discussed and has broadened to the larger debate asking if D-serine may be considered as a gliotransmitter like glutamate and ATP (Wolosker et al., 2016, 2017; Papouin et al., 2017). Indeed, the initial characterization of SR expression in astrocytes (Wolosker et al., 1999) and the view that different NMDAR-dependent functions could be driven by a vesicular release of $\mathrm{D}$-serine from this subtype of glial cells (Yang et al., 2005; Panatier et al., 2006; Williams et al., 2006; Martineau et al., 2008; Papouin et al., 2012; Martineau, 2013; Lalo et al., 2018; Robin et al., 2018) are now strongly questioned. This is mainly due to the development of more selective SR antibodies and improved immunohistochemical protocols, to the lack in those pre-cited experiments of negative controls with SR knock-out $\left(\mathrm{SR}^{-/-}\right)$ mice which display a $90 \%$ decrease in brain D-serine without significant changes in levels of the other amino acids except D-aspartate (Miya et al., 2008; Basu et al., 2009), and finally because the use of mice with disrupted SNARE-dependent exocytosis in astrocytes to specifically assess glio-transmission is still under debate (Fiacco and McCarthy, 2018; Savtchouk 
and Volterra, 2018). When rigorous experimental conditions are achieved in vivo, SR is mainly expressed in excitatory neurons and GABAergic inhibitory interneurons of the human and rodent brains with only a weak if any detection in astrocytes (Kartvelishvily et al., 2006; Miya et al., 2008; Benneyworth et al., 2012; Ehmsen et al., 2013; Balu et al., 2014; Perez et al., 2017). Nowadays, an emerging concept of a serine shuttle gathers increasing interest (Wolosker, 2011; Wolosker and Radzishevsky, 2013) in which it is viewed that through orchestrated activities of neutral amino acid transporters including at least alanineserine-cysteine 1 (Asc-1) and ASCT1 subtypes (Rosenberg et al., 2013; Sason et al., 2017; Kaplan et al., 2018), the astrocytederived precursor L-serine fuels the neuronal SR to produce D-serine, which is then released to bind NMDAR before to be subsequently removed from synapses by either neurons or astrocytes (Figure 2). Although this shuttle sounds attractive to account for the synaptic turnover of D-serine in the healthy brain though it needs to be definitively validated, it fails to work when pathological conditions associated with astrogliosis prevail, such as those occurring in traumatic brain injury for example. Indeed, a controlled cortical brain insult results in a downregulation of neuronal SR expression and a parallel increase in reactive astrocytes (Perez et al., 2017), that thus devotes a major role in vivo to glia-derived D-serine only when pathological mechanisms inducing excitotoxic damages and neuronal death are promoted.

In addition to help for a better determination cellular localization of SR, lessons from $\mathrm{SR}^{-/-}$mice have also provided information for a pivotal role of the SR-associated processes in controlling functional plasticity at synapses. This has been particularly investigated using the electrophysiological paradigm of long-term potentiation (LTP) of synaptic transmission, a form of long lasting form of synaptic plasticity now viewed as a major functional requirement for memory formation (Izquierdo, 1991; Bear and Malenka, 1994; Collingridge and Bliss, 1995; Izquierdo and Medina, 1995; Lisman and McIntyre, 2001; Kim and Linden, 2007). Indeed, LTP is significantly reduced ex vivo in slice preparations isolated from mice with specific deletion of SR in neurons using the calmodulin kinase II promoter or in vivo using the Thy1-mediated Cre recombination, the deficits being rescued in both cases by exogenous D-serine (Benneyworth et al., 2012; Perez et al., 2017). On the contrary, similar designs but selectively targeting astrocytes using the GFAP promoter has no significant impact on LTP expression (Benneyworth et al., 2012). These results provide additional functional evidences that SR-induced D-serine from glia plays a minor role in synaptic plasticity in healthy conditions, in opposition to what is claimed (Panatier et al., 2006; Henneberger et al., 2010; Papouin et al., 2012; Lalo et al., 2018). However, it is worth noting that glia-derived D-serine could impact functional plasticity when pathological conditions prevail as recently reported after traumatic brain injury where the induction of SR expression in reactive astrocytes associated with an excessive release of D-serine, impairs LTP expression (Perez et al., 2017) and behavior (Liraz-Zaltsman et al., 2018). Whether similar deleterious effects of glia-derived D-serine on synaptic plasticity also occur in other astrogliosisassociated brain injuries remains to be determined.
The SR-dependent modulation of functional plasticity involves changes in NMDAR activation in response to altered D-serine availability. Indeed, isolated NMDAR-dependent excitatory postsynaptic currents (EPSCs) show slower decay kinetics in $\mathrm{SR}^{-/-}$mice (Basu et al., 2009; Balu et al., 2013) while the amplitude of miniature NMDAR-EPSCs are significantly reduced in mice with selective neuronal SR deletion (Benneyworth et al., 2012). Providing exogenous D-serine to SR-deleted animals not only rescues these functional deficits but also increases the amplitude of NMDAR-dependent currents more extensively than in wild-type animals, consistent with lower occupancy of the NMDAR glycine-binding site when SR is invalidated.

SR is functionally modulated by a wide range of regulatory mechanisms including changes in cofactors likely to be present in the vicinity of the enzyme, protein interactions, dynamic changes in subcellular localization and posttranslational processes (recently reviewed and detailed in Wolosker, 2018). An increase in SR activity, due to activation or the prevention of its degradation, may be promoted by the small ligands ATP and $\mathrm{Mg}^{2+}$ (De Miranda et al., 2002; Strísovský et al., 2003; Foltyn et al., 2005), multiple protein interactors including GRIP, Golga3, Disc-1 and FBXO22 (Kim et al., 2005; Dumin et al., 2006; Ma et al., 2013; Dikopoltsev et al., 2014), by Opalmitoylation-related processes (Balan et al., 2009) and also possibly through phosphorylation at different residues (Balan et al., 2009; Foltyn et al., 2010). On the other hand, nicotinamide adeninedinucleotide (NADH) (Suzuki et al., 2015; Bruno et al., 2016), protein interactions with Pick-1 (Fujii et al., 2006), PSD95 (Ma et al., 2014; Lin et al., 2016), SAP102 and stargazin (Ma et al., 2014), membrane or nuclear translocations (Balan et al., 2009; Kolodney et al., 2015) and S-Nitrosylation-related oxidative processes (Mustafa et al., 2007) inhibit SR activity. Therefore, the SR activity itself appears to be modulated in a complex manner by a large mosaic of mechanisms, which can be targeted by the aging process.

\section{DOWN REGULATION OF SR-RELATED ACTIVITY IN PHYSIOLOGICAL AGING}

Changes in neurologic functions generally occur with physiological aging that may substantially interfere with everyday activities (Craik and Bialystok, 2006). Indeed, older adults experience deficits in learning and memory while the speed of cognitive processing is frequently slowed down, that have initially been associated with neuroanatomical changes (BrunsoBechtold et al., 2000; Driscoll et al., 2003; Finch, 2003; Geinisman et al., 2004; Hayakawa et al., 2007; Burke and Barnes, 2010). However, lessons from numerous preclinical investigations now rather support the view that impaired expression of NMDARdependent functional plasticity at synaptic connections is the major cellular substrate of physiological cognitive aging (Lynch, 1998; Barnes, 2003; Billard, 2006; Foster, 2012). A decrease in NMDAR density, and notably in GluN2B subunits, was initially suspected to underlie LTP deficits in the aging brain (Magnusson, 1998, 2000; Clayton et al., 2002a,b; Magnusson et al., 2002; Bai 


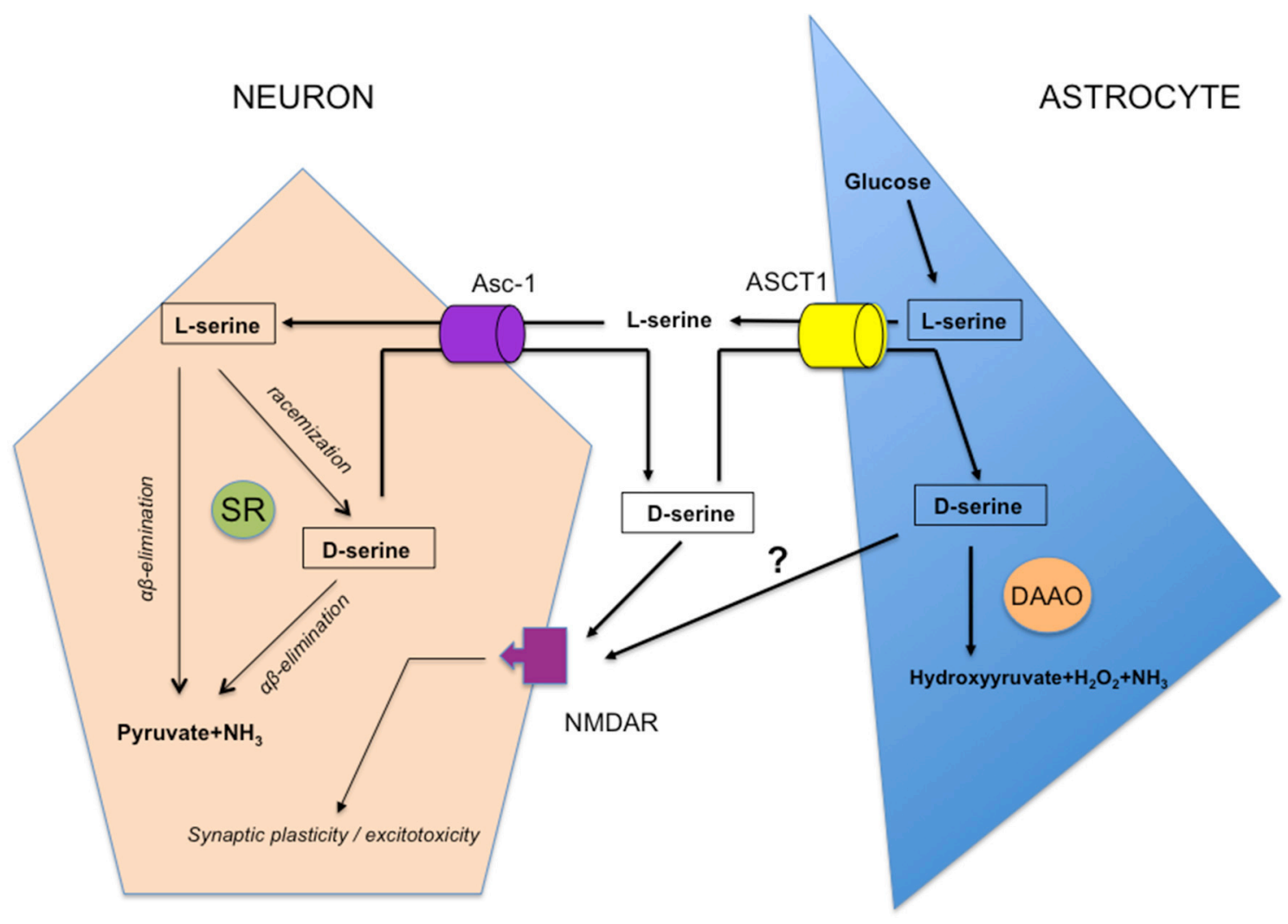

FIGURE 2 | Schematic representation of the serine shuttle. L-serine specifically synthesized from glucose in the astrocyte subtype of glial cells, is released in external medium through the Alanine, serine, cysteine, threonine (ASCT1) subtype of neutral amino acid transporters. It is then taken-up by neurons through the Asc-1 subtype where it is converted into D-serine by serine racemase (SR) while part of the amino acid may be degraded into pyruvate and $\mathrm{NH}_{3}$ by $\alpha, \beta$ elimination of water. $\mathrm{D}$-serine is delivered back to extracellular space through Asc- 1 hetero-exchange with L-serine to act on NMDAR thus promoting functional plasticity at synapses or neurotoxicity in pathological conditions. D-serine is taken-up from the synaptic cleft through ASCT1 hetero-exchange with L-serine in astrocytes where it is degraded by $\mathrm{D}$-amino acid oxidase (DAAO) activity. Whether part of D-serine-derived astrocytes may be released to impact NMDAR is under debate.

et al., 2004; Brim et al., 2013) but defects affecting the functional modulation of the receptor have also been later characterized including deregulation at the redox site (Kuehl-Kovarik et al., 2003; Bodhinathan et al., 2010; Yang et al., 2010; Kumar et al., 2017), changes in non-competitive blockade (Norris and Foster, 1999) and even altered lipid composition of postsynaptic membranes (Lynch and Voss, 1994; McGahon et al., 1999; Latour et al., 2013). In the search of such functional deficits, changes in SR-modulation of NMDAR activation has also been postulated to develop with age (Billard, 2013). According to this possibility, aged humans with impaired memory capacities in the Groton maze computer test improve their performances if they previously receive a D-serine-enriched drink (Avellar et al., 2016) while learning deficits in aged drosophila in an olfactory conditioning is rescued by feeding the flies with the amino acid (Yamazaki et al., 2014). Subsequent analyses in aged rodents indicate that a reduced SR expression is a prominent feature of hippocampal aging (Figure 3A), which decreases $\mathrm{D}$-serine levels within neuronal networks and promotes NMDAR hypofunction (Mothet et al., 2006; Potier et al., 2010; Turpin et al., 2011). Providing the amino acid to the "aged" tissues then restores NMDAR activation and LTP induction at synapses (Yang et al., 2005; Mothet et al., 2006; Turpin et al., 2011). In animal models of successful cognitive aging such as the LOU/C strain of rats (Alliot et al., 2002; Kappeler et al., 2004), the potent memory abilities and NMDAR-dependent LTP displayed by aged individuals correlate with preserved SR expression and D-serine production (Kollen et al., 2010; Turpin et al., 2011). One characteristic of aged LOU/C rats is to present high resistance to oxidative stress (OS) induced by the accumulation of free radical damages that progressively take place in the course of aging (Sohal and Weindruch, 1996; Golden et al., 2002; Ali et al., 2006; Dröge and Schipper, 2007). Increased oxidation of sulfydryl groups of SR (Mustafa et al., 2007) and/or changes in its dimer active conformation (Wang and Barger, 2012) could then be viewed as critical mechanisms driven by OS to impact SR activation in the aging brain. Accordingly, long-term treatment with the reducing agent $\mathrm{N}$-acetyl cysteine in aged rats to prevent from OS development, protects SR expression and activity and preserves a potent NMDAR activation in the animals (Haxaire et al., 2012). In addition, weaker SR activity promoted by OS could also be managed through an hypermethylation in the 
A

PHYSIOLOGICAL AGEING
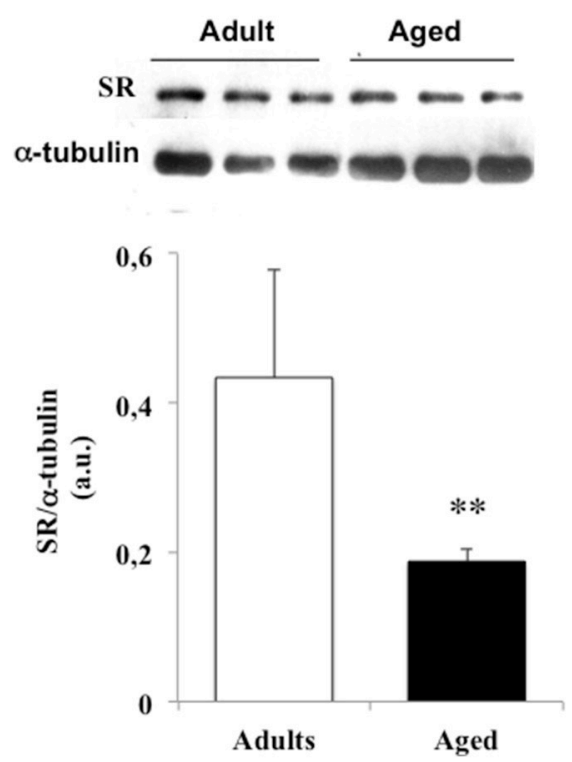

B

\section{ALZHEIMER'S DISEASE}
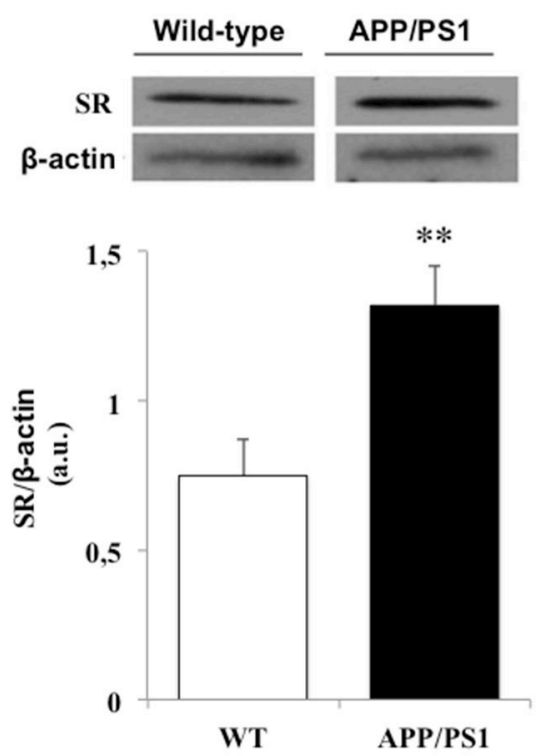

FIGURE 3 | Serine racemase (SR) expression is down and up regulated in physiological and pathological brain aging respectively. (A) Examples of immunoblots for serine racemase (SR) and $\alpha$-tubulin in adult and aged rats (up) and bar graphs depicted the mean SR expression determined for each group when normalized to $\alpha$-tubulin (down). (B). Examples of immunoblots for SR and $\beta$-actin in a wild-type (WT) and an APP/PS1 mouse model of Alzheimer's disease (up) and bar graphs depicted the mean SR expression determined for each group when normalized to $\beta$-actin (down). (**P < 0.01). Modified with permissions from (Potier et al., 2010) and (Madeira et al., 2015).

promoter of SR gene (Zhang et al., 2015) that could explain the age-related decreased levels of SR transcripts (Mothet et al., 2006; Potier et al., 2010). These results therefore reinforce the idea of preventing oxidative stress as a major strategy to alleviate cognitive aging (Sohal and Weindruch, 1996; Liu et al., 2003; Dröge and Schipper, 2007).

Besides the OS-dependent dysfunctions of SR activation, a down-regulation of its enzymatic activity could also be viewed in the aging brain as resulting from a reduced synaptic availability of L-serine (postulated in Ivanov and Mothet, 2018). However, though the expression of PHGDH, one of the enzymes predominantly involved in the synthesis pathway of the Dserine precursor (Yamasaki et al., 2001), is reduced in acutely isolated astrocytes from aged mice (Orre et al., 2014; Holtman et al., 2015), overall levels of the amino acid are not altered in the aging hippocampus (Mothet et al., 2006; Turpin et al., 2011; Haxaire et al., 2012) and providing L-serine does not help in preventing the age-related decrease in NMDAR activation (Junjaud et al., 2006). On the other hand, recent evidence reports that the D-serine shuttle, and notably the potency of the Asc1 transporters to release $\mathrm{D}$-serine from neurons, is not affected by age (Billard and Freret, 2018). These results further indicate that changes in SR-related modulation of NMDAR represent a critical mechanism associated with physiological brain aging and that boosting SR activation could thus be viewed to represent an alternative strategy to alleviate age-related memory impairment.
Among different possibilities, a strategy based on SR stimulation by $\mathrm{Mg}^{2+}$ could be hypothesized considering that $\mathrm{Mg}^{2+}$ has been shown to enhance learning and memory (Ozturk and Cillier, 2006; Slutsky et al., 2010).

\section{UP REGULATION OF SR-RELATED ACTIVITY IN ALZHEIMER'S DISEASE}

Compared to other neurological disorders such as schizophrenia, depression or amyotrophic lateral sclerosis (Goltsov et al., 2006; Labrie and Roder, 2010; Mitchell et al., 2010; Gómez-Galán et al., 2012; Balu and Coyle, 2015; Coyle and Balu, 2018), our current knowledge on the role of the SR-related pathway in the pathophysiology of Alzheimer's disease (AD) is so far limited. One reason for this weaker interest probably comes from the initial biochemical observations indicating that free $\mathrm{D}$-serine levels were not consistently altered in the brain of $\mathrm{AD}$ patients, although the percentage of $\mathrm{D}$-serine in the total $(D+L)$ serine was significantly lower than that of aged-matched controls (Chouinard et al., 1993; Kumashiro et al., 1995; Nagata et al., 1995; Hashimoto et al., 2004; Biemans et al., 2016) but see (Fisher et al., 1998). Nevertheless, the absence of a clear-cut contribution of SR to AD-related pathophysiology could reflect the fact that the levels of D-serine in those experiments were determined in patients at late stages of the pathology whereas the 
most recent preclinical studies suggest that the amino acid could rather be involved in the very early steps of the disease (Madeira et al., 2015). Indeed, a significant increase in D-serine levels has recently been characterized in the cerebrospinal fluid (CSF) of subjects with only mild cognitive impairment that will probably evolve into dementia (Madeira et al., 2015). This observation has suggested that a deregulation of the SR-related activity could serve as a new biomarker of the entry into the pathology [see also (Hashimoto et al., 2004)], although this postulate has not recently been confirmed (Biemans et al., 2016). Nevertheless, several preclinical data strongly argue for the involvement of SR in the pathophysiological processes underlying $\mathrm{AD}$. Thus, two major soluble factors involved in $\mathrm{AD}$ pathogenesis, the amyloid $ß$-peptide $(A ß)$ and the secreted form of $B$-amyloid precursor protein (APP) (Cline et al., 2018), stimulate SR expression and promote D-serine release in microglial cell cultures whereas these subtypes of glial cells do not normally produce the amino acid (Wu et al., 2004, 2007). The Aß peptide evokes D-serine synthesis and efflux also from neurons, in synergy with the release of glutamate (Brito-Moreira et al., 2011; Madeira et al., 2015) that drives over-stimulation of NMDAR and promotes neurotoxicity, a typical picture of the pathophysiology of $\mathrm{AD}$ (Harkany et al., 2000; Butterfield, 2002; Hynd et al., 2004). Several other preclinical observations fit well with a contribution of $\mathrm{D}$ serine in AD-related neurotoxicity: neuronal cell death induced by NMDA is strongly reduced in cerebral tissues depleted in Dserine after a pre-treatment with DAAO (Katsuki et al., 2004) as well as in organotypic hippocampal slices pre-treated with the recombinant $\mathrm{D}$-serine deaminase, an enzyme 100 fold more active than DAAO in degrading the amino acid (Shleper et al., 2005). In vivo, both NMDAR and Aß-induced neurotoxicity are largely attenuated in $\mathrm{SR}^{-/-}$mice (Inoue et al., 2008). Through the binding of inducible proto-oncogenes $c$-fos and JunB to the activator protein-1 sequence present on the first intron of the SR gene, $A ß$ promotes the transcriptional induction of SR (Wu and Barger, 2004), an observation which fits with the increase in SR messenger RNAs in the brain of AD patients (Wu et al., 2004). Post-transcriptional mechanisms may also contribute such as an increase in intracellular calcium levels by Aß (Wu et al., 2004) knowing that calcium overload in neurons is able to boost SR activity (Cook et al., 2002; De Miranda et al., 2002).

Besides, a significant increase in SR expression and D-serine levels also occur in vivo in a mouse model of $\mathrm{AD}$ with a transgene for APP associated with a mutant form of presenilin 1 (APP/PS1 mice) (Figure 3B) (Madeira et al., 2015). Finally, recent preliminary data indicate that in the $5 \mathrm{xFAD}$ model of $\mathrm{AD}$ which expresses high levels of soluble Aß oligomers (Oakley et al., 2006; Giannoni et al., 2013; Lee and Han, 2013), the impaired functional plasticity reported at hippocampal synapses (Kimura and Ohno, 2009; Crouzin et al., 2013) was rescued after deleting the SR gene, that further points out a major role of an altered SRdependent modulation of NMDAR functions in the Aß-related pathophysiology of AD (Billard et al., 2018).

Considering the current state of knowledge summarized above, the elevated SR expression and the subsequent increase in D-serine levels in the extracellular space could be viewed as pro-death signals in $\mathrm{AD}$ that promotes, in

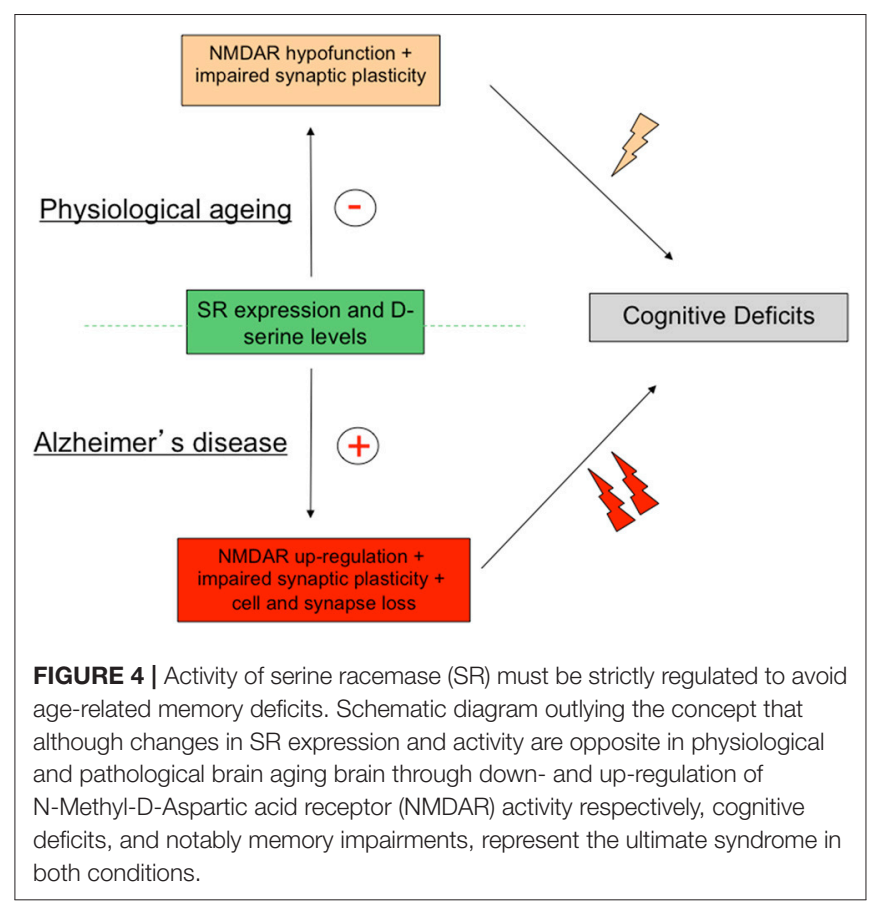

conjunction with the release of glutamate, the neurotoxicity exhibited by inflammatory processes (Barger et al., 2007; Vesce et al., 2007). Although this view clearly remains to be definitively characterized and notably if the glia-derived SR could contribute to mechanisms of the insult, the upregulation of the SR-related pathway in $\mathrm{AD}$ therefore appears as a perfect example of how a deregulation of allosteric modulation of NMDAR may drive the onset of pathological conditions.

\section{CONCLUSION}

Nowadays, a wealth of preclinical and clinical evidences argues for a critical role of SR throughout lifespan in the regulation of functional plasticity through the synaptic availability of the NMDAR co-agonist D-serine. Such modulation impacting NMDAR activation allows the enzyme to control many brain functions in healthy conditions while being a preferential target for pathophysiological insults (Coyle and Balu, 2018). When interest is focused on age-related memory disabilities, a down- and up-regulation of the SR-associated pathway are specifically associated with physiological aging and $\mathrm{AD}$ respectively. Although these alterations show striking opposite directions, they both result in fine in memory deficits indicating that a strict control of SR expression and activity is required to achieve a successful cognitive aging (Figure 4). These results therefore highlight SR as a potent target for the development of alternative pharmacological interventions aimed at relieving cognitive impairments linked to the aging process. Protection of SR to the age-related oxidative stress is already suggested to represent such an alternative procedure to rescue memory deficits associated with physiological aging (Haxaire et al., 
2012). In preclinical studies, SR antagonists such as Phenazine Ethosulfate (Phen-Et) and erythro- $\beta$-Hydroxy L-aspartate have been used to investigate SR involvement in specific NMDARdependent processes (De Miranda et al., 2002; Kim et al., 2005; Strísovský et al., 2005; Stevens et al., 2010), that could represent other pharmacological alternatives to prevent the onset of pathological conditions in which SR activity is facilitated such as ALS, AD or brain trauma (Sasabe et al., 2007; Madeira et al., 2015; Lee et al., 2017; Perez et al., 2017; Kondori et al., 2018), though the specificity of these pharmacological tools have recently been questioned. However, there is no doubt now that increasing our knowledge of SR-dependent regulation of NMDAR activation certainly represents a key route that

\section{REFERENCES}

Ali, S. S., Xiong, C., Lucero, J., Behrens, M. M., Dugan, L. L., and Quick, K. L. (2006). Gender differences in free radical homeostasis during aging: shorter-lived female C57BL6 mice have increased oxidative stress. Aging Cell 5, 565-574. doi: 10.1111/j.1474-9726.2006.00252.x

Alliot, J., Boghossian, S., Jourdan, D., Veyrat-Durebex, C., Pickering, G., MeynialDenis, D., et al. (2002). The LOU/c/jall rat as an animal model of healthy aging? J. Gerontol. A Biol. Sci. Med. Sci. 57, B312-320. doi: 10.1093/gerona/57.8.B312

Avellar, M., Scoriels, L., Madeira, C., Vargas-Lopes, C., Marques, P., Dantas, C., et al. (2016). The effect of D-serine administration on cognition and mood in older adults. Oncotarget 7, 11881-11888. doi: 10.18632/oncotarget.7691

Bai, L., Hof, P. R., Standaert, D. G., Xing, Y., Nelson, S. E., Young, A. B., et al. (2004). Changes in the expression of the NR2B subunit during aging in macaque monkeys. Neurobiol. Aging 25, 201-208. doi: 10.1016/S0197-4580(03)00091-5

Bai, Y., Zhou, L., Wu, X., and Dong, Z. (2014). D-serine enhances fear extinction by increasing GluA2-containing AMPA receptor endocytosis. Behav. Brain Res. 270, 223-227. doi: 10.1016/j.bbr.2014.05.025

Balan, L., Foltyn, V. N., Zehl, M., Dumin, E., Dikopoltsev, E., Knoh, D., et al. (2009). Feedback inactivation of D-serine synthesis by NMDA receptor-elicited translocation of serine racemase to the membrane. Proc. Natl. Acad. Sci. U.S.A. 106, 7589-7594. doi: 10.1073/pnas.0809442106

Ballard, T. M., Pauly-Evers, M., Higgins, G. A., Ouagazzal, A. M., Mutel, V., Borroni, E., et al. (2002). Severe impairment of NMDA receptor function in mice carrying targeted point mutations in the glycine binding site results in drug-resistant nonhabituating hyperactivity. J. Neurosci. 22, 6713-6723. doi: 10.1523/JNEUROSCI.22-15-06713.2002

Balu, D. T., and Coyle, J. T. (2012). Neuronal D-serine regulates dendritic architecture in the somatosensory cortex. Neurosci. Lett. 517, 77-81. doi: 10.1016/j.neulet.2012.04.020

Balu, D. T., and Coyle, J. T. (2015). The NMDA receptor 'glycine modulatory site' in schizophrenia: D-serine, glycine, and beyond. Curr. Opin. Pharmacol. 20, 109-115. doi: 10.1016/j.coph.2014.12.004

Balu, D. T., Li, Y., Puhl, M. D., Benneyworth, M. A., Basu, A. C., Takagi, S., et al. (2013). Multiple risk pathways for schizophrenia converge in serine racemase knockout mice, a mouse model of NMDA receptor hypofunction. Proc. Natl. Acad. Sci. U.S.A. 110, E2400-2409. doi: 10.1073/pnas.1304308110

Balu, D. T., Presti, K. T., Huang, C. C. Y., Muszynski, K., Radzishevsky, I., Wolosker, H., et al. (2018). Serine racemase and D-serine in the amygdala are dynamically involved in fear learning. Biol. Psychiatry 83, 273-283. doi: 10.1016/j.biopsych.2017.08.012

Balu, D. T., Takagi, S., Puhl, M. D., Benneyworth, M. A., and Coyle, J. T. (2014). D-serine and serine racemase are localized to neurons in the adult mouse and human forebrain. Cell. Mol. Neurobiol. 34, 419-435. doi: 10.1007/s10571-014-0027-z

Bardaweel, S. K., Alzweiri, M., and Ishaqat, A. A. (2014). D-serine in neurobiology: CNS neurotransmission and neuromodulation. Can. J. Neurol. Sci. 41, 164-176. doi: $10.1017 /$ S031716710001653X will help people keeping potent cognitive abilities throughout lifespan.

\section{AUTHOR CONTRIBUTIONS}

The author confirms being the sole contributor of this work and has approved it for publication.

\section{ACKNOWLEDGMENTS}

J-MB is supported by the Institut National de la Santé et de la Recherche Médicale (INSERM) and by the fondation France Alzheimer.

Barger, S. W., Goodwin, M. E., Porter, M. M., and Beggs, M. L. (2007). Glutamate release from activated microglia requires the oxidative burst and lipid peroxidation. J. Neurochem. 101, 1205-1213. doi: 10.1111/j.1471-4159.2007.04487.x

Barnes, C. A. (2003). Long-term potentiation and the ageing brain. Philos. Trans. R. Soc. Lond. B Biol. Sci. 358, 765-772. doi: 10.1098/rstb.2002.1244

Basu, A. C., Tsai, G. E., Ma, C. L., Ehmsen, J. T., Mustafa, A. K., Han, L., et al. (2009). Targeted disruption of serine racemase affects glutamatergic neurotransmission and behavior. Mol. Psychiatry 14, 719-727. doi: 10.1038/mp.2008.130

Bear, M. F., and Malenka, R. C. (1994). Synaptic plasticity: LTP and LTD. Curr. Opin. Neurobiol. 4, 389-399. doi: 10.1016/0959-4388(94)90101-5

Bendikov, I., Nadri, C., Amar, S., Panizzutti, R., De Miranda, J., Wolosker, H., et al. (2007). A CSF and postmortem brain study of D-serine metabolic parameters in schizophrenia. Schizophr. Res. 90, 41-51. doi: 10.1016/j.schres.2006.10.010

Benneyworth, M. A., and Coyle, J. T. (2012). Altered acquisition and extinction of amphetamine-paired context conditioning in genetic mouse models of altered NMDA receptor function. Neuropsychopharmacology 37, 2496-2504. doi: 10.1038/npp.2012.108

Benneyworth, M. A., Li, Y., Basu, A. C., Bolshakov, V. Y., and Coyle, J. T. (2012). Cell selective conditional null mutations of serine racemase demonstrate a predominate localization in cortical glutamatergic neurons. Cell. Mol. Neurobiol. 32, 613-624. doi: 10.1007/s10571-012-9808-4

Biemans, E. A., Verhoeven-Duif, N. M., Gerrits, J., Claassen, J. A., Kuiperij, H. B., and Verbeek, M. M. (2016). CSF d-serine concentrations are similar in Alzheimer's disease, other dementias, and elderly controls. Neurobiol. Aging 42, 213-216. doi: 10.1016/j.neurobiolaging.2016.03.017

Billard, J., Ploux, E., Gorisse-Hussonois, L., and Freret, T. (2018). "Dserine contributes to beta-amyloid-dependent pathophysiology in Alzheimer's Disease,"in 11rd (C010) Forum Neuroscience (Berlin).

Billard, J. M. (2006). Ageing, hippocampal synaptic activity and magnesium. Magnes. Res. 19, 199-215. doi: 10.1684/mrh.2006.0063

Billard, J. M. (2008). D-serine signalling as a prominent determinant of neuronalglial dialogue in the healthy and diseased brain. J. Cell. Mol. Med. 12, 1872-1884. doi: 10.1111/j.1582-4934.2008.00315.x

Billard, J. M. (2012). D-Amino acids in brain neurotransmission and synaptic plasticity. Amino Acids 43, 1851-1860. doi: 10.1007/s00726-012-1346-3

Billard, J. M. (2013). Serine racemase as a prime target for age-related memory deficits. Eur. J. Neurosci. 37, 1931-1938. doi: 10.1111/ejn. 12226

Billard, J. M., and Freret, T. (2018). Asc-1 transporter activation: an alternative to rescue age-related alterations in functional plasticity at rat hippocampal CA3/CA1 synapses. J. Neurochem. doi: 10.1111/jnc.14586. [Epub ahead of print].

Bodhinathan, K., Kumar, A., and Foster, T. C. (2010). Intracellular redox state alters NMDA receptor response during aging through Ca2+/calmodulin-dependent protein kinase II. J. Neurosci. 30, 1914-1924. doi: 10.1523/JNEUROSCI.5485-09.2010

Brim, B. L., Haskell, R., Awedikian, R., Ellinwood, N. M., Jin, L., Kumar, A., et al. (2013). Memory in aged mice is rescued by enhanced expression of 
the GluN2B subunit of the NMDA receptor. Behav. Brain Res. 238, 211-226. doi: 10.1016/j.bbr.2012.10.026

Brito-Moreira, J., Paula-Lima, A. C., Bomfim, T. R., Oliveira, F. B., Sepulveda, F. J., De Mello, F. G., et al. (2011). Abeta oligomers induce glutamate release from hippocampal neurons. Curr. Alzheimer Res. 8, 552-562. doi: 10.2174/156720511796391917

Brown, R. E., Stevens, D. R., and Haas, H. L. (2001). The physiology of brain histamine. Prog. Neurobiol. 63, 637-672. doi: 10.1016/S0301-0082(00)00039-3

Bruno, S., Marchesani, F., Dellafiora, L., Margiotta, M., Faggiano, S., Campanini, B., et al. (2016). Human serine racemase is allosterically modulated by $\mathrm{NADH}$ and reduced nicotinamide derivatives. Biochem. J. 473, 3505-3516. doi: 10.1042/BCJ20160566

Brunso-Bechtold, J. K., Linville, M. C., and Sonntag, W. E. (2000). Age-related synaptic changes in sensorimotor cortex of the Brown Norway X fischer 344 rat. Brain Res. 872, 125-133. doi: 10.1016/S0006-8993(00)02515-4

Burke, S. N., and Barnes, C. A. (2010). Senescent synapses and hippocampal circuit dynamics. Trends Neurosci. 33, 153-161. doi: 10.1016/j.tins.2009. 12.003

Butterfield, D. A. (2002). Amyloid beta-peptide (1-42)-induced oxidative stress and neurotoxicity: implications for neurodegeneration in Alzheimer's disease brain. A review. Free Radic. Res. 36, 1307-1313. doi: 10.1080/10715760210000 49890

Choi, Y. B., and Lipton, S. A. (2000). Redox modulation of the NMDA receptor. Cell. Mol. Life Sci. 57, 1535-1541. doi: 10.1007/PL00000638

Chouinard, M. L., Gaitan, D., and Wood, P. L. (1993). Presence of the N-methyl$\mathrm{D}$-aspartate-associated glycine receptor agonist, D-serine, in human temporal cortex: comparison of normal, Parkinson, and Alzheimer tissues. J. Neurochem. 61, 1561-1564. doi: 10.1111/j.1471-4159.1993.tb13657.x

Clayton, D. A., Grosshans, D. R., and Browning, M. D. (2002a). Aging and surface expression of hippocampal NMDA receptors. J. Biol. Chem. 277, 14367-14369. doi: 10.1074/jbc.C200074200

Clayton, D. A., Mesches, M. H., Alvarez, E., Bickford, P. C., and Browning, M. D. (2002b). A hippocampal NR2B deficit can mimic age-related changes in longterm potentiation and spatial learning in the Fischer 344 rat. J. Neurosci. 22, 3628-3637. doi: 10.1523/JNEUROSCI.22-09-03628.2002

Cline, E. N., Bicca, M. A., Viola, K. L., and Klein, W. L. (2018). The amyloidbeta oligomer hypothesis: beginning of the third decade. J. Alzheimers. Dis. 64, S567-s610. doi: 10.3233/JAD-179941

Collingridge, G. L., and Bliss, T. V. (1995). Memories of NMDA receptors and LTP. Trends Neurosci. 18, 54-56. doi: 10.1016/0166-2236(95)80016-U

Cook, S. P., Galve-Roperh, I., Martinez del Pozo, A., and Rodriguez-Crespo, I. (2002). Direct calcium binding results in activation of brain serine racemase. J. Biol. Chem. 277, 27782-27792. doi: 10.1074/jbc.M111814200

Coyle, J. T. (2006). Substance use disorders and Schizophrenia: a question of shared glutamatergic mechanisms. Neurotox. Res. 10, 221-233. doi: 10.1007/BF03033359

Coyle, J. T., and Balu, D. T. (2018). The role of serine racemase in the pathophysiology of brain disorders. Adv. Pharmacol. 82, 35-56. doi: 10.1016/bs.apha.2017.10.002

Craik, F. I., and Bialystok, E. (2006). Cognition through the lifespan: mechanisms of change. Trends Cogn. Sci. 10, 131-138. doi: 10.1016/j.tics.2006.01.007

Crouzin, N., Baranger, K., Cavalier, M., Marchalant, Y., Cohen-Solal, C., Roman, F. S., et al. (2013). Area-specific alterations of synaptic plasticity in the 5XFAD mouse model of Alzheimer's disease: dissociation between somatosensory cortex and hippocampus. PLoS ONE 8:e74667. doi: 10.1371/journal.pone.0074667

De Miranda, J., Panizzutti, R., Foltyn, V. N., and Wolosker, H. (2002). Cofactors of serine racemase that physiologically stimulate the synthesis of the N-methylD-aspartate (NMDA) receptor coagonist D-serine. Proc. Natl. Acad. Sci. U.S.A. 99, 14542-14547. doi: 10.1073/pnas.222421299

Dikopoltsev, E., Foltyn, V. N., Zehl, M., Jensen, O. N., Mori, H., Radzishevsky, I., et al. (2014). FBXO22 protein is required for optimal synthesis of the Nmethyl-D-aspartate (NMDA) receptor coagonist D-serine. J. Biol. Chem. 289, 33904-33915. doi: 10.1074/jbc.M114.618405

Dingledine, R., Borges, K., Bowie, D., and Traynelis, S. F. (1999). The glutamate receptor ion channels. Pharmacol. Rev. 51, 7-61.

Driscoll, I., Hamilton, D. A., Petropoulos, H., Yeo, R. A., Brooks, W. M., Baumgartner, R. N., et al. (2003). The aging hippocampus: cognitive, biochemical and structural findings. Cereb. Cortex 13, 1344-1351. doi: 10.1093/cercor/bhg081

Dröge, W., and Schipper, H. M. (2007). Oxidative stress and aberrant signaling in aging and cognitive decline. Aging Cell 6, 361-370. doi: 10.1111/j.1474-9726.2007.00294.x

Dumin, E., Bendikov, I., Foltyn, V. N., Misumi, Y., Ikehara, Y., Kartvelishvily, E., et al. (2006). Modulation of D-serine levels via ubiquitin-dependent proteasomal degradation of serine racemase. J. Biol. Chem. 281, 20291-20302. doi: 10.1074/jbc.M601971200

Dunah, A. W., Yasuda, R. P., Luo, J., Wang, Y., Prybylowski, K. L., and Wolfe, B. B. (1999). Biochemical studies of the structure and function of the N-methylD-aspartate subtype of glutamate receptors. Mol. Neurobiol. 19, 151-179. doi: 10.1007/BF02743658

Ehmsen, J. T., Ma, T. M., Sason, H., Rosenberg, D., Ogo, T., Furuya, S., et al. (2013). $\mathrm{D}$-serine in glia and neurons derives from 3-phosphoglycerate dehydrogenase. J. Neurosci. 33, 12464-12469. doi: 10.1523/JNEUROSCI.4914-12.2013

Fiacco, T. A., and McCarthy, K. D. (2018). Multiple lines of evidence indicate that gliotransmission does not occur under physiological conditions. J. Neurosci. 38, 3-13. doi: 10.1523/JNEUROSCI.0016-17.2017

Finch, C. E. (2003). Neurons, glia, and plasticity in normal brain aging. Neurobiol Aging 24 (Suppl. 1), S123-127; discussion S131. doi: 10.1016/S0197-4580(03)00051-4

Fisher, G., Lorenzo, N., Abe, H., Fujita, E., Frey, W. H., Emory, C., et al. (1998). Free D- and L-amino acids in ventricular cerebrospinal fluid from Alzheimer and normal subjects. Amino Acids 15, 263-269. doi: 10.1007/BF01318865

Foltyn, V. N., Bendikov, I., De Miranda, J., Panizzutti, R., Dumin, E., Shleper, M., et al. (2005). Serine racemase modulates intracellular D-serine levels through an alpha,beta-elimination activity. J. Biol. Chem. 280, 1754-1763. doi: 10.1074/jbc.M405726200

Foltyn, V. N., Zehl, M., Dikopoltsev, E., Jensen, O. N., and Wolosker, H. (2010). Phosphorylation of mouse serine racemase regulates D-serine synthesis. FEBS Lett. 584, 2937-2941. doi: 10.1016/j.febslet.2010.05.022

Foster, T. C. (2012). Dissecting the age-related decline on spatial learning and memory tasks in rodent models: N-methyl-D-aspartate receptors and voltagedependent Ca2+ channels in senescent synaptic plasticity. Prog. Neurobiol. 96, 283-303. doi: 10.1016/j.pneurobio.2012.01.007

Fujii, K., Maeda, K., Hikida, T., Mustafa, A. K., Balkissoon, R., Xia, J., et al. (2006). Serine racemase binds to PICK1: potential relevance to schizophrenia. Mol. Psychiatry 11, 150-157. doi: 10.1038/sj.mp.4001776

Geinisman, Y., Ganeshina, O., Yoshida, R., Berry, R. W., Disterhoft, J. F., and Gallagher, M. (2004). Aging, spatial learning, and total synapse number in the rat CA1 stratum radiatum. Neurobiol. Aging 25, 407-416. doi: 10.1016/j.neurobiolaging.2003.12.001

Giannoni, P., Gaven, F., de Bundel, D., Baranger, K., Marchetti-Gauthier, E., Roman, F. S., et al. (2013). Early administration of RS 67333, a specific 5HT4 receptor agonist, prevents amyloidogenesis and behavioral deficits in the 5XFAD mouse model of Alzheimer's disease. Front. Aging Neurosci. 5:96. doi: 10.3389/fnagi.2013.00096

Golden, T. R., Hinerfeld, D. A., and Melov, S. (2002). Oxidative stress and aging: beyond correlation. Aging Cell 1, 117-123. doi: 10.1046/j.1474-9728.2002.00015.x

Goltsov, A. Y., Loseva, J. G., Andreeva, T. V., Grigorenko, A. P., Abramova, L. I., Kaleda, V. G., et al. (2006). Polymorphism in the 5'-promoter region of serine racemase gene in schizophrenia. Mol. Psychiatry 11, 325-326. doi: 10.1038/sj.mp.4001801

Gómez-Galán, M., De Bundel, D., Van Eeckhaut, A., Smolders, I., and Lindskog, M. (2012). Dysfunctional astrocytic regulation of glutamate transmission in a rat model of depression. Mol. Psychiatry 18, 582-94. doi: 10.1038/mp.2012.10

Haas, H. L., Sergeeva, O. A., and Selbach, O. (2008). Histamine in the nervous system. Physiol. Rev. 88, 1183-1241. doi: 10.1152/physrev.00043.2007

Harkany, T., Abraham, I., Konya, C., Nyakas, C., Zarandi, M., Penke, B., et al. (2000). Mechanisms of beta-amyloid neurotoxicity: perspectives of pharmacotherapy. Rev. Neurosci. 11, 329-382. doi: 10.1515/REVNEURO.2000.11.4.329

Hashimoto, K., Fukushima, T., Shimizu, E., Okada, S., Komatsu, N., Okamura, N., et al. (2004). Possible role of D-serine in the pathophysiology of Alzheimer's disease. Prog. Neuropsychopharmacol. Biol. Psychiatry 28, 385-388. doi: 10.1016/j.pnpbp.2003.11.009 
Haxaire, C., Turpin, F. R., Potier, B., Kervern, M., Sinet, P. M., Barbanel, G., et al. (2012). Reversal of age-related oxidative stress prevents hippocampal synaptic plasticity deficits by protecting d-serine-dependent NMDA receptor activation. Aging Cell 11, 336-344. doi: 10.1111/j.1474-9726.2012.00792.x

Hayakawa, N., Kato, H., and Araki, T. (2007). Age-related changes of astorocytes, oligodendrocytes and microglia in the mouse hippocampal CA1 sector. Mech. Ageing Dev. 128, 311-316. doi: 10.1016/j.mad.2007.01.005

Henneberger, C., Bard, L., and Rusakov, D. A. (2012). D-Serine: a key to synaptic plasticity? Int. J. Biochem. Cell Biol. 44, 587-590. doi: 10.1016/j.biocel.2012.01.005

Henneberger, C., Papouin, T., Oliet, S. H., and Rusakov, D. A. (2010). Longterm potentiation depends on release of D-serine from astrocytes. Nature 463, 232-236. doi: 10.1038/nature08673

Hofmann, K., Tomiuk, S., Wolff, G., and Stoffel, W. (2000). Cloning and characterization of the mammalian brain-specific, $\mathrm{Mg} 2+$-dependent neutral sphingomyelinase. Proc. Natl. Acad. Sci. U.S.A. 97, 5895-5900. doi: 10.1073/pnas.97.11.5895

Holtman, I. R., Raj, D. D., Miller, J. A., Schaafsma, W., Yin, Z., Brouwer, N., et al. (2015). Induction of a common microglia gene expression signature by aging and neurodegenerative conditions: a co-expression meta-analysis. Acta Neuropathol. Commun. 3:31. doi: 10.1186/s40478-015-0203-5

Hynd, M. R., Scott, H. L., and Dodd, P. R. (2004). Glutamate-mediated excitotoxicity and neurodegeneration in Alzheimer's disease. Neurochem. Int. 45, 583-595. doi: 10.1016/j.neuint.2004.03.007

Inoue, R., Hashimoto, K., Harai, T., and Mori, H. (2008). NMDA- and betaamyloid1-42-induced neurotoxicity is attenuated in serine racemase knock-out mice. J. Neurosci. 28, 14486-14491. doi: 10.1523/JNEUROSCI.5034-08.2008

Inoue, R., Talukdar, G., Takao, K., Miyakawa, T., and Mori, H. (2018). Dissociated role of $\mathrm{D}$-serine in extinction during consolidation vs. reconsolidation of context conditioned fear. Front Mol Neurosci 11:161. doi: 10.3389/fnmol.2018.00161

Ivanov, A. D., and Mothet, J. P. (2018). The plastic d-serine signaling pathway: sliding from neurons to glia and vice-versa. Neurosci. Lett. doi: 10.1016/j.neulet.2018.05.039. [Epub ahead of print].

Izquierdo, I. (1991). Role of NMDA receptors in memory. Trends Pharmacol. Sci. 12, 128-129. doi: 10.1016/0165-6147(91)90527-Y

Izquierdo, I., and Medina, J. H. (1995). Correlation between the pharmacology of long-term potentiation and the pharmacology of memory. Neurobiol. Learn. Mem. 63, 19-32. doi: 10.1006/nlme.1995.1002

Jagannath, V., Marinova, Z., Monoranu, C. M., Walitza, S., and Grunblatt, E. (2017). Expression of D-Amino Acid Oxidase (DAO/DAAO) and D-Amino Acid Oxidase Activator (DAOA/G72) during development and aging in the human post-mortem brain. Front. Neuroanat. 11:31. doi: $10.3389 /$ fnana.2017.00031

Johnson, J. W., and Ascher, P. (1987). Glycine potentiates the NMDA response in cultured mouse brain neurons. Nature 325, 529-531. doi: 10.1038/ $325529 \mathrm{a} 0$

Johnson, J. W., and Ascher, P. (1990). Voltage-dependent block by intracellular $\mathrm{Mg} 2+$ of N-methyl-D-aspartate-activated channels. Biophys. J. 57, 1085-1090. doi: 10.1016/S0006-3495(90)82626-6

Johnson, J. W., and Ascher, P. (1992). Equilibrium and kinetic study of glycine action on the N-methyl-D-aspartate receptor in cultured mouse brain neurons. J. Physiol. 455, 339-365. doi: 10.1113/jphysiol.1992. sp019305

Junjaud, G., Rouaud, E., Turpin, F., Mothet, J. P., and Billard, J. M. (2006). Age-related effects of the neuromodulator D-serine on neurotransmission and synaptic potentiation in the CA1 hippocampal area of the rat. J. Neurochem. 98 , 1159-1166. doi: 10.1111/j.1471-4159.2006.03944.x

Kaplan, E., Zubedat, S., Radzishevsky, I., Valenta, A. C., Rechnitz, O., Sason, H., et al. (2018). ASCT1 (Slcla4) transporter is a physiologic regulator of brain d-serine and neurodevelopment. Proc. Natl. Acad. Sci. U.S.A. 115, 9628-9633. doi: 10.1073/pnas.1722677115

Kappeler, L., Zizzari, P., Alliot, J., Epelbaum, J., and Bluet-Pajot, M. T. (2004). Delayed age-associated decrease in growth hormone pulsatile secretion and increased orexigenic peptide expression in the Lou C/JaLL rat. Neuroendocrinology 80, 273-283. doi: 10.1159/000083610

Kartvelishvily, E., Shleper, M., Balan, L., Dumin, E., and Wolosker, H. (2006). Neuron-derived D-serine release provides a novel means to activate N-methyl-D-aspartate receptors. J. Biol. Chem. 281, 14151-14162. doi: 10.1074/jbc.M512927200

Katsuki, H., Nonaka, M., Shirakawa, H., Kume, T., and Akaike, A. (2004). Endogenous D-serine is involved in induction of neuronal death by $\mathrm{N}$-methyl$\mathrm{D}$-aspartate and simulated ischemia in rat cerebrocortical slices. J. Pharmacol. Exp. Ther. 311, 836-844. doi: 10.1124/jpet.104.070912

Kim, P. M., Aizawa, H., Kim, P. S., Huang, A. S., Wickramasinghe, S. R., Kashani, A. H., et al. (2005). Serine racemase: activation by glutamate neurotransmission via glutamate receptor interacting protein and mediation of neuronal migration. Proc. Natl. Acad. Sci. U.S.A. 102, 2105-2110. doi: $10.1073 /$ pnas.0409723102

Kim, S. J., and Linden, D. J. (2007). Ubiquitous plasticity and memory storage. Neuron 56, 582-592. doi: 10.1016/j.neuron.2007.10.030

Kimura, R., and Ohno, M. (2009). Impairments in remote memory stabilization precede hippocampal synaptic and cognitive failures in 5XFAD Alzheimer mouse model. Neurobiol. Dis. 33, 229-235. doi: 10.1016/j.nbd.2008.10.006

Kleckner, N. W., and Dingledine, R. (1988). Requirement for glycine in activation of NMDA-receptors expressed in Xenopus oocytes. Science 241, 835-837. doi: 10.1126/science.2841759

Kleckner, N. W., and Dingledine, R. (1991). Regulation of hippocampal NMDA receptors by magnesium and glycine during development. Brain Res. Mol. Brain Res. 11, 151-159.

Kollen, M., Stephan, A., Faivre-Bauman, A., Loudes, C., Sinet, P. M., Alliot, J., et al. (2010). Preserved memory capacities in aged Lou/C/Jall rats. Neurobiol. Aging 31, 129-142. doi: 10.1016/j.neurobiolaging.2008.03.010

Kolodney, G., Dumin, E., Safory, H., Rosenberg, D., Mori, H., Radzishevsky, I., et al. (2015). Nuclear compartmentalization of serine racemase regulates Dserine production: Implications for N-Methyl-D-Aspartate (NMDA) receptor activation. J. Biol. Chem. 290, 31037-31050. doi: 10.1074/jbc.M115.699496

Kondori, N. R., Paul, P., Robbins, J. P., Liu, K., Hildyard, J. C. W., Wells, D. J., et al. (2018). Focus on the role of D-serine and D-amino acid oxidase in Amyotrophic Lateral Sclerosis/Motor Neuron Disease (ALS). Front Mol Biosci. 5:8. doi: 10.3389/fmolb.2018.00008

Kuehl-Kovarik, M. C., Partin, K. M., and Magnusson, K. R. (2003). Acute dissociation for analyses of NMDA receptor function in cortical neurons during aging. J. Neurosci. Methods 129, 11-17. doi: 10.1016/S0165-0270(03)00196-1

Kumar, A., Yegla, B., and Foster, T. C. (2017). Redox signaling in neurotransmission and cognition during aging. Antioxid. Redox Signal. 28, 1724-45. doi: 10.1089/ars.2017.7111

Kumashiro, S., Hashimoto, A., and Nishikawa, T. (1995). Free Dserine in post-mortem brains and spinal cords of individuals with and without neuropsychiatric diseases. Brain Res. 681, 117-125. doi: 10.1016/0006-8993(95)00307-C

Labrie, V., Fukumura, R., Rastogi, A., Fick, L. J., Wang, W., Boutros, P. C., et al. (2009). Serine racemase is associated with schizophrenia susceptibility in humans and in a mouse model. Hum. Mol. Genet. 18, 3227-3243. doi: $10.1093 / \mathrm{hmg} / \mathrm{ddp} 261$

Labrie, V., and Roder, J. C. (2010). The involvement of the NMDA receptor $\mathrm{D}$-serine/glycine site in the pathophysiology and treatment of schizophrenia. Neurosci. Biobehav. Rev. 34, 351-372. doi: 10.1016/j.neubiorev.2009. 08.002

Lalo, U., Bogdanov, A., and Pankratov, Y. (2018). Diversity of astroglial effects on aging- and experience-related cortical metaplasticity. Front. Mol. Neurosci. 11:239. doi: 10.3389/fnmol.2018.00239

Latour, A., Grintal, B., Champeil-Potokar, G., Hennebelle, M., Lavialle, M., Dutar, P., et al. (2013). Omega-3 fatty acids deficiency aggravates glutamatergic synapse and astroglial aging in the rat hippocampal CA1. Aging Cell 12, 76-84. doi: 10.1111/acel.12026

Laurie, D. J., and Seeburg, P. H. (1994). Regional and developmental heterogeneity in splicing of the rat brain NMDAR1 mRNA. J. Neurosci. 14(5 Pt 2), 3180-3194. doi: 10.1523/JNEUROSCI.14-05-03180.1994

Le Bail, M., Martineau, M., Sacchi, S., Yatsenko, N., Radzishevsky, I., Conrod, S., et al. (2015). Identity of the NMDA receptor coagonist is synapse specific and developmentally regulated in the hippocampus. Proc. Natl. Acad. Sci. U.S.A. 112, E204-213. doi: 10.1073/pnas.1416668112

Lee, J. E., and Han, P. L. (2013). An update of animal models of Alzheimer disease with a reevaluation of plaque depositions. Exp. Neurobiol. 22, 84-95. doi: $10.5607 /$ en.2013.22.2.84 
Lee, N. Y., Kim, Y., Ryu, H., and Kang, Y. S. (2017). The alteration of serine transporter activity in a cell line model of amyotrophic lateral sclerosis (ALS). Biochem. Biophys. Res. Commun. 483, 135-141. doi: 10.1016/j.bbrc.2016.12.178

Lin, H., Jacobi, A. A., Anderson, S. A., and Lynch, D. R. (2016). D-serine and serine racemase are associated with PSD-95 and glutamatergic synapse stability. Front. Cell. Neurosci. 10:34. doi: 10.3389/fncel.2016.00034

Lipton, S. A., Rayudu, P. V., Choi, Y. B., Sucher, N. J., and Chen, H. S. (1998). Redox modulation of the NMDA receptor by NO-related species. Prog. Brain Res. 118, 73-82. doi: 10.1016/S0079-6123(08)63201-X

Liraz-Zaltsman, S., Slusher, B., Atrakchi-Baranes, D., Rosenblatt, K., Friedman Levi, Y., Kesner, E., et al. (2018). Enhancement of brain d-serine mediates recovery of cognitive function after traumatic brain injury. J. Neurotrauma 35:1667-1680 doi: 10.1089/neu.2017.5561

Lisman, J. E., and McIntyre, C. C. (2001). Synaptic plasticity: a molecular memory switch. Curr. Biol. 11, R788-791. doi: 10.1016/S0960-9822(01) 00472-9

Liu, R., Liu, I. Y., Bi, X., Thompson, R. F., Doctrow, S. R., Malfroy, B., et al. (2003). Reversal of age-related learning deficits and brain oxidative stress in mice with superoxide dismutase/catalase mimetics. Proc. Natl. Acad. Sci. U.S.A. 100, 8526-8531. doi: 10.1073/pnas.1332809100

Liu, X. B., Murray, K. D., and Jones, E. G. (2004). Switching of NMDA receptor $2 \mathrm{~A}$ and $2 \mathrm{~B}$ subunits at thalamic and cortical synapses during early postnatal development. J. Neurosci. 24, 8885-8895. doi: 10.1523/JNEUROSCI.2476-04.2004

Lynch, M. A. (1998). Age-related impairment in long-term potentiation in hippocampus: a role for the cytokine, interleukin-1 beta? Prog. Neurobiol. 56, 571-589. doi: 10.1016/S0301-0082(98)00054-9

Lynch, M. A., and Voss, K. L. (1994). Membrane arachidonic acid concentration correlates with age and induction of long-term potentiation in the dentate gyrus in the rat. Eur. J. Neurosci. 6, 1008-1014. doi: 10.1111/j.1460-9568.1994.tb00595.x

Ma, T. M., Abazyan, S., Abazyan, B., Nomura, J., Yang, C., Seshadri, S., et al. (2013). Pathogenic disruption of DISC1-serine racemase binding elicits schizophrenia-like behavior via D-serine depletion. Mol. Psychiatry 18, 557-567. doi: 10.1038/mp.2012.97

Ma, T. M., Paul, B. D., Fu, C., Hu, S., Zhu, H., Blackshaw, S., et al. (2014). Serine racemase regulated by binding to stargazin and PSD-95: potential N-methylD-aspartate-alpha-amino-3-hydroxy-5-methyl-4-isoxazolepropionic acid (NMDA-AMPA) glutamate neurotransmission cross-talk. J. Biol. Chem. 289, 29631-29641. doi: 10.1074/jbc.M114.571604

Madeira, C., Lourenco, M. V., Vargas-Lopes, C., Suemoto, C. K., Brandão CO., Reis, T., et al. (2015). d-serine levels in Alzheimer's disease: implications for novel biomarker development. Transl. Psychiatry 5:e561. doi: $10.1038 /$ tp. 2015.52

Magnusson, K. R. (1998). The aging of the NMDA receptor complex. Front. Biosci. 3, e70-80. doi: 10.2741/A368

Magnusson, K. R. (2000). Declines in mRNA expression of different subunits may account for differential effects of aging on agonist and antagonist binding to the NMDA receptor. J. Neurosci. 20, 1666-1674. doi: 10.1523/JNEUROSCI.20-05-01666.2000

Magnusson, K. R., Nelson, S. E., and Young, A. B. (2002). Age-related changes in the protein expression of subunits of the NMDA receptor. Brain Res. Mol. Brain Res. 99, 40-45. doi: 10.1016/S0169-328X(01)00344-8

Martineau, M. (2013). Gliotransmission: focus on exocytotic release of Lglutamate and D-serine from astrocytes. Biochem. Soc. Trans. 41, 1557-1561. doi: 10.1042/BST20130195

Martineau, M., Galli, T., Baux, G., and Mothet, J. P. (2008). Confocal imaging and tracking of the exocytotic routes for D-serine-mediated gliotransmission. Glia 56, 1271-1284. doi: 10.1002/glia.20696

McGahon, B. M., Martin, D. S., Horrobin, D. F., and Lynch, M. A. (1999). Age-related changes in synaptic function: analysis of the effect of dietary supplementation with omega-3 fatty acids. Neuroscience 94, 305-314. doi: 10.1016/S0306-4522(99)00219-5

Mitchell, J., Paul, P., Chen, H. J., Morris, A., Payling, M., Falchi, M., et al. (2010). Familial amyotrophic lateral sclerosis is associated with a mutation in D-amino acid oxidase. Proc. Natl. Acad. Sci. U.S.A. 107, 7556-7561. doi: 10.1073/pnas.0914128107
Miya, K., Inoue, R., Takata, Y., Abe, M., Natsume, R., Sakimura, K., et al. (2008). Serine racemase is predominantly localized in neurons in mouse brain. J. Comp. Neurol. 510, 641-654. doi: 10.1002/cne.21822

Monyer, H., Burnashev, N., Laurie, D. J., Sakmann, B., and Seeburg, P. H. (1994). Developmental and regional expression in the rat brain and functional properties of four NMDA receptors. Neuron 12, 529-540. doi: 10.1016/0896-6273(94)90210-0

Mothet, J. P., Le Bail, M., and Billard, J. M. (2015). Time and space profiling of NMDA receptor co-agonist functions. J. Neurochem. 135, 210-225. doi: $10.1111 /$ jnc. 13204

Mothet, J. P., Parent, A. T., Wolosker, H., Brady, R. O. Jr., Linden, D. J., Ferris, C. D., et al. (2000). D-serine is an endogenous ligand for the glycine site of the N-methyl-D-aspartate receptor. Proc. Natl. Acad. Sci. U.S.A. 97, 4926-4931. doi: 10.1073/pnas.97.9.4926

Mothet, J. P., Rouaud, E., Sinet, P. M., Potier, B., Jouvenceau, A., Dutar, P., et al. (2006). A critical role for the glial-derived neuromodulator D-serine in the agerelated deficits of cellular mechanisms of learning and memory. Aging Cell 5, 267-274. doi: 10.1111/j.1474-9726.2006.00216.x

Mustafa, A. K., Kumar, M., Selvakumar, B., Ho, G. P., Ehmsen, J. T., Barrow, R. K., et al. (2007). Nitric oxide S-nitrosylates serine racemase, mediating feedback inhibition of D-serine formation. Proc. Natl. Acad. Sci. U.S.A. 104, 2950-2955. doi: $10.1073 /$ pnas. 0611620104

Nagata, Y., Borghi, M., Fisher, G. H., and D’Aniello, A. (1995). Free D-serine concentration in normal and Alzheimer human brain. Brain Res. Bull. 38, 181-183. doi: 10.1016/0361-9230(95)00087-U

Nakanishi, S., and Masu, M. (1994). Molecular diversity and functions of glutamate receptors. Annu. Rev. Biophys. Biomol. Struct. 23, 319-348. doi: 10.1146/annurev.bb.23.060194.001535

Norris, C. M., and Foster, T. C. (1999). MK-801 improves retention in aged rats: implications for altered neural plasticity in age-related memory deficits. Neurobiol. Learn. Mem. 71, 194-206. doi: 10.1006/nlme.1998.3864

Oakley, H., Cole, S. L., Logan, S., Maus, E., Shao, P., Craft, J., et al. (2006). Intraneuronal beta-amyloid aggregates, neurodegeneration, and neuron loss in transgenic mice with five familial Alzheimer's disease mutations: potential factors in amyloid plaque formation. J. Neurosci. 26, 10129-10140. doi: 10.1523/JNEUROSCI.1202-06.2006

Orre, M., Kamphuis, W., Osborn, L. M., Melief, J., Kooijman, L., Huitinga, I., et al. (2014). Acute isolation and transcriptome characterization of cortical astrocytes and microglia from young and aged mice. Neurobiol. Aging 35, 1-14. doi: 10.1016/j.neurobiolaging.2013.07.008

Ozturk, S., and Cillier, A. E. (2006). Magnesium supplementation in the treatment of dementia patients. Med. Hypotheses 67, 1223-1225. doi: 10.1016/j.mehy.2006.04.047

Panatier, A., Theodosis, D. T., Mothet, J. P., Touquet, B., Pollegioni, L., Poulain, D. A., et al. (2006). Glia-derived D-serine controls NMDA receptor activity and synaptic memory. Cell 125, 775-784. doi: 10.1016/j.cell.2006.02.051

Paoletti, P. (2011). Molecular basis of NMDA receptor functional diversity. Eur. J. Neurosci. 33, 1351-1365. doi: 10.1111/j.1460-9568.2011.07628.x

Paoletti, P., Bellone, C., and Zhou, Q. (2013). NMDA receptor subunit diversity: impact on receptor properties, synaptic plasticity and disease. Nat. Rev. Neurosci. 14, 383-400. doi: 10.1038/nrn3504

Papouin, T., Henneberger, C., Rusakov, D. A., and Oliet, S. H. R. (2017). Astroglial versus neuronal D-serine: fact checking. Trends Neurosci. 40, 517-520. doi: 10.1016/j.tins.2017.05.007

Papouin, T., Ladepeche, L., Ruel, J., Sacchi, S., Labasque, M., Hanini, M., et al. (2012). Synaptic and extrasynaptic NMDA receptors Are gated by different endogenous coagonists. Cell 150, 633-646. doi: 10.1016/j.cell.2012.06.029

Perez, E. J., Tapanes, S. A., Loris, Z. B., Balu, D. T., Sick, T. J., Coyle, J. T., et al. (2017). Enhanced astrocytic d-serine underlies synaptic damage after traumatic brain injury. J. Clin. Invest. 127, 3114-3125. doi: 10.1172/JCI92300

Pollegioni, L., Piubelli, L., Sacchi, S., Pilone, M. S., and Molla, G. (2007). Physiological functions of D-amino acid oxidases: from yeast to humans. Cell. Mol. Life Sci. 64, 1373-1394. doi: 10.1007/s00018-007-6558-4

Potier, B., Turpin, F. R., Sinet, P. M., Rouaud, E., Mothet, J. P., Videau, C., et al. (2010). Contribution of the d-serine-dependent pathway to the cellular mechanisms underlying cognitive aging. Front. Aging Neurosci. 2:1. doi: $10.3389 /$ neuro. 24.001 .2010 
Puhl, M. D., Desai, R. I., Takagi, S., Presti, K. T., Doyle, M. R., Donahue, R. J., et al. (2017). N-Methyl-d-aspartate receptor co-agonist availability affects behavioral and neurochemical responses to cocaine: insights into comorbid schizophrenia and substance abuse. Addict. Biol. doi: 10.1111/adb.12577. [Epub ahead of print].

Robin, L. M., Oliveira da Cruz, J. F., Langlais, V. C., Martin-Fernandez, M., Metna-Laurent, M., Busquets-Garcia, A., et al. (2018). Astroglial CB1 receptors determine synaptic D-serine availability to enable recognition memory. Neuron 98, 935-944.e935. doi: 10.1016/j.neuron.2018.04.034

Rosenberg, D., Artoul, S., Segal, A. C., Kolodney, G., Radzishevsky, I., Dikopoltsev, E., et al. (2013). Neuronal D-serine and glycine release via the Asc-1 transporter regulates NMDA receptor-dependent synaptic activity. J. Neurosci. 33, 3533-3544. doi: 10.1523/JNEUROSCI.3836-12.2013

Sasabe, J., Chiba, T., Yamada, M., Okamoto, K., Nishimoto, I., Matsuoka, M., et al. (2007). D-serine is a key determinant of glutamate toxicity in amyotrophic lateral sclerosis. EMBO J. 26, 4149-4159. doi: 10.1038/sj.emboj.7601840

Sason, H., Billard, J. M., Smith, G. P., Safory, H., Neame, S., Kaplan, E., et al. (2017). Asc-1 transporter regulation of synaptic activity via the tonic release of $\mathrm{d}$-serine in the forebrain. Cereb. Cortex 27, 1573-1587. doi: 10.1093/cercor/bhv350

Savtchouk, I., and Volterra, A. (2018). Gliotransmission: Beyond Black-and-White. J. Neurosci. 38, 14-25. doi: 10.1523/JNEUROSCI.0017-17.2017

Schell, M. J., Brady, R. O. Jr., Molliver, M. E., and Snyder, S. H. (1997). D-serine as a neuromodulator: regional and developmental localizations in rat brain glia resemble NMDA receptors. J. Neurosci. 17, 1604-1615. doi: 10.1523/JNEUROSCI.17-05-01604.1997

Shleper, M., Kartvelishvily, E., and Wolosker, H. (2005). D-serine is the dominant endogenous coagonist for NMDA receptor neurotoxicity in organotypic hippocampal slices. J. Neurosci. 25, 9413-9417. doi: 10.1523/JNEUROSCI.3190-05.2005

Slutsky, I., Abumaria, N., Wu, L. J., Huang, C., Zhang, L., Li, B., et al. (2010). Enhancement of learning and memory by elevating brain magnesium. Neuron 65, 165-177. doi: 10.1016/j.neuron.2009.12.026

Snyder, S. H., and Kim, P. M. (2000). D-amino acids as putative neurotransmitters: focus on D-serine. Neurochem. Res. 25, 553-560. doi: 10.1023/A:1007586314648

Sohal, R. S., and Weindruch, R. (1996). Oxidative stress, caloric restriction, and aging. Science 273, 59-63. doi: 10.1126/science.273.5271.59

Stevens, E. R., Gustafson, E. C., Sullivan, S. J., Esguerra, M., and Miller, R. F. (2010). Light-evoked NMDA receptor-mediated currents are reduced by blocking D-serine synthesis in the salamander retina. Neuroreport 21, 239-244. doi: 10.1097/WNR.0b013e32833313b7

Stocca, G., and Vicini, S. (1998). Increased contribution of NR2A subunit to synaptic NMDA receptors in developing rat cortical neurons. J. Physiol. 507 (Pt 1), 13-24. doi: 10.1111/j.1469-7793.1998.013bu.x

Strick, C. A., Li, C., Scott, L., Harvey, B., Hajos, M., Steyn, S. J., et al. (2011). Modulation of NMDA receptor function by inhibition of Damino acid oxidase in rodent brain. Neuropharmacology 61, 1001-1015. doi: 10.1016/j.neuropharm.2011.06.029

Strísovský, K., Jiraskova, J., Barinka, C., Majer, P., Rojas, C., Slusher, B. S., et al. (2003). Mouse brain serine racemase catalyzes specific elimination of L-serine to pyruvate. FEBS Lett. 535, 44-48. doi: 10.1016/S0014-5793(02) 03855-3

Strísovský, K., Jiraskova, J., Mikulova, A., Rulisek, L., and Konvalinka, J. (2005). Dual substrate and reaction specificity in mouse serine racemase: identification of high-affinity dicarboxylate substrate and inhibitors and analysis of the beta-eliminase activity. Biochemistry 44, 13091-13100. doi: 10.1021/ bi051201o

Sun, Y., Cheng, X., Zhang, L., Hu, J., Chen, Y., Zhan, L., et al. (2017). The functional and molecular properties, physiological functions, and pathophysiological roles of GluN2A in the central nervous system. Mol. Neurobiol. 54, 1008-1021. doi: 10.1007/s12035-016-9715-7

Suzuki, M., Sasabe, J., Miyoshi, Y., Kuwasako, K., Muto, Y., Hamase, K., et al. (2015). Glycolytic flux controls D-serine synthesis through glyceraldehyde3-phosphate dehydrogenase in astrocytes. Proc. Natl. Acad. Sci. U.S.A. 112, E2217-2224. doi: 10.1073/pnas.1416117112

Swanger, S. A., and Traynelis, S. F. (2018). Synaptic receptor diversity revealed across space and time. Trends Neurosci. 41, 486-488. doi: 10.1016/j.tins.2018.06.001
Traynelis, S. F., Wollmuth, L. P., McBain, C. J., Menniti, F. S., Vance, K. M., Ogden, K. K., et al. (2010). Glutamate receptor ion channels: structure, regulation, and function. Pharmacol. Rev. 62, 405-496. doi: 10.1124/pr.109.002451

Turpin, F. R., Potier, B., Dulong, J. R., Sinet, P. M., Alliot, J., Oliet, S. H., et al. (2011). Reduced serine racemase expression contributes to age-related deficits in hippocampal cognitive function. Neurobiol. Aging 32, 1495-1504. doi: 10.1016/j.neurobiolaging.2009.09.001

Ulbrich, M. H., and Isacoff, E. Y. (2008). Rules of engagement for NMDA receptor subunits. Proc. Natl. Acad. Sci. U.S.A. 105, 14163-14168. doi: 10.1073/pnas.0802075105

Verrall, L., Walker, M., Rawlings, N., Benzel, I., Kew, J. N., Harrison, P. J., et al. (2007). d-Amino acid oxidase and serine racemase in human brain: normal distribution and altered expression in schizophrenia. Eur. J. Neurosci. 26, 1657-1669. doi: 10.1111/j.1460-9568.2007.05769.x

Vesce, S., Rossi, D., Brambilla, L., and Volterra, A. (2007). Glutamate release from astrocytes in physiological conditions and in neurodegenerative disorders characterized by neuroinflammation. Int. Rev. Neurobiol. 82, 57-71. doi: 10.1016/S0074-7742(07)82003-4

Wang, D., Jacobs, S. A., and Tsien, J. Z. (2014). Targeting the NMDA receptor subunit NR2B for treating or preventing age-related memory decline. Expert Opin. Ther. Targets 18, 1121-1130. doi: 10.1517/14728222.2014.941286

Wang, W., and Barger, S. W. (2012). Cross-linking of serine racemase dimer by reactive oxygen species and reactive nitrogen species. J. Neurosci. Res. 90, 1218-1229. doi: 10.1002/jnr.22832

Williams, S. M., Diaz, C. M., Macnab, L. T., Sullivan, R. K., and Pow, D. V. (2006). Immunocytochemical analysis of $\mathrm{D}$-serine distribution in the mammalian brain reveals novel anatomical compartmentalizations in glia and neurons. Glia 53, 401-411. doi: 10.1002/glia.20300

Wolosker, H. (2011). Serine racemase and the serine shuttle between neurons and astrocytes. Biochim. Biophys. Acta 1814, 1558-1566. doi: 10.1016/j.bbapap.2011.01.001

Wolosker, H. (2018). The neurobiology of d-serine signaling. Adv. Pharmacol. 82, 325-348. doi: 10.1016/bs.apha.2017.08.010

Wolosker, H., Balu, D. T., and Coyle, J. T. (2016). The rise and fall of the dserine-mediated gliotransmission hypothesis. Trends Neurosci. 39, 712-721. doi: 10.1016/j.tins.2016.09.007

Wolosker, H., Balu, D. T., and Coyle, J. T. (2017). Astroglial versus neuronal D-serine: check your controls! Trends Neurosci. 40, 520-522. doi: 10.1016/j.tins.2017.06.010

Wolosker, H., Blackshaw, S., and Snyder, S. H. (1999). Serine racemase: a glial enzyme synthesizing $\mathrm{D}$-serine to regulate glutamate-N-methyl-Daspartate neurotransmission. Proc. Natl. Acad. Sci. U.S.A. 96, 13409-13414. doi: $10.1073 /$ pnas.96.23.13409

Wolosker, H., and Radzishevsky, I. (2013). The serine shuttle between glia and neurons: implications for neurotransmission and neurodegeneration. Biochem. Soc. Trans. 41, 1546-1550. doi: 10.1042/BST20130220

$\mathrm{Wu}, \mathrm{S}$., and Barger, S. W. (2004). Induction of serine racemase by inflammatory stimuli is dependent on AP-1. Ann. N. Y. Acad. Sci. 1035, 133-146. doi: 10.1196/annals.1332.009

Wu, S., Basile, A. S., and Barger, S. W. (2007). Induction of serine racemase expression and $\mathrm{D}$-serine release from microglia by secreted amyloid precursor protein (sAPP). Curr. Alzheimer Res. 4, 243-251. doi: 10.2174/156720507781077241

Wu, S. Z., Bodles, A. M., Porter, M. M., Griffin, W. S., Basile, A. S., and Barger, S. W. (2004). Induction of serine racemase expression and D-serine release from microglia by amyloid beta-peptide. J. Neuroinflammation 1:2. doi: 10.1186/1742-2094-1-2

Wyllie, D. J., Livesey, M. R., and Hardingham, G. E. (2013). Influence of GluN2 subunit identity on NMDA receptor function. Neuropharmacology 74, 4-17. doi: 10.1016/j.neuropharm.2013.01.016

Yamasaki, M., Yamada, K., Furuya, S., Mitoma, J., Hirabayashi, Y., and Watanabe, M. (2001). 3-Phosphoglycerate dehydrogenase, a key enzyme for l-serine biosynthesis, is preferentially expressed in the radial glia/astrocyte lineage and olfactory ensheathing glia in the mouse brain. J. Neurosci. 21, 7691-7704. doi: 10.1523/JNEUROSCI.21-19-07691.2001

Yamazaki, D., Horiuchi, J., Ueno, K., Ueno, T., Saeki, S., Matsuno, M., et al. (2014). Glial dysfunction causes age-related memory impairment in Drosophila. Neuron 84, 753-763. doi: 10.1016/j.neuron.2014.09.039 
Yang, S., Qiao, H., Wen, L., Zhou, W., and Zhang, Y. (2005). D-serine enhances impaired long-term potentiation in CA1 subfield of hippocampal slices from aged senescence-accelerated mouse prone/8. Neurosci. Lett. 379, 7-12. doi: 10.1016/j.neulet.2004.12.033

Yang, Y. J., Wu, P. F., Long, L. H., Yu, D. F., Wu, W. N., Hu, Z. L., et al. (2010). Reversal of aging-associated hippocampal synaptic plasticity deficits by reductants via regulation of thiol redox and NMDA receptor function. Aging Cell 9, 709-721. doi: 10.1111/j.1474-9726.2010.00595.x

Zhang, H., Kuang, X. L., Chang, Y., Lu, J., Jiang, H., and Wu, S. (2015). Reduced serine racemase expression in aging rat cerebellum is associated with oxidative DNA stress and hypermethylation in the promoter. Brain Res. 1629, 221-230. doi: 10.1016/j.brainres.2015.10.034

Zhang, X. M., and Luo, J. H. (2013). GluN2A versus GluN2B: twins, but quite different. Neurosci. Bull. 29, 761-772. doi: 10.1007/s12264-013$1336-9$
Zhu, S., and Paoletti, P. (2015). Allosteric modulators of NMDA receptors: multiple sites and mechanisms. Curr. Opin. Pharmacol. 20, 14-23. doi: 10.1016/j.coph.2014.10.009

Conflict of Interest Statement: The author declares that the research was conducted in the absence of any commercial or financial relationships that could be construed as a potential conflict of interest.

Copyright (c) 2018 Billard. This is an open-access article distributed under the terms of the Creative Commons Attribution License (CC BY). The use, distribution or reproduction in other forums is permitted, provided the original author(s) and the copyright owner(s) are credited and that the original publication in this journal is cited, in accordance with accepted academic practice. No use, distribution or reproduction is permitted which does not comply with these terms. 